\title{
Tracking of high-temperature thermal expansion and transport properties vs. oxidation state of cobalt between +2 and +3 in the $\mathrm{La}_{2} \mathrm{Co}_{1+z}\left(\mathrm{Ti}_{1-x} \mathrm{Mg}_{x}\right)_{1-z} \mathrm{O}_{6}$-system
}

${ }^{1}$ S. Shafeie, ${ }^{1}$ J. Grins, ${ }^{2}$ S. Ya. Istomin, ${ }^{2}$ A. A. Gippius, ${ }^{3}$ L. Karvonen, ${ }^{3}$ S. Populoh, ${ }^{3}$ A. Weidenkaff, ${ }^{4}$ J. Köhler and ${ }^{1}$ G. Svensson

${ }^{1}$ Department of Materials and Environmental Chemistry, Stockholm University, SE-106 91 Stockholm

${ }^{2}$ M. V. Lomonosov Moscow State University, 119991 Moscow, Russia

${ }^{3}$ Laboratory for Solid State Chemistry and Catalysis, EMPA - Swiss Federal Laboratories for Materials Science and Technology, CH-8600 Dübendorf, Switzerland

${ }^{4}$ Max Planck Institute for Solid State Research, Heisenbergstraße 1, 70569 Stuttgart, Germany

\section{Corresponding author:}

Samrand Shafeie

Department of Materials and Environmental Chemistry, Stockholm University, SE-106 91 Stockholm, Sweden 


\section{Abstract}

The high-temperature thermal expansion and electronic transport properties of the B-site substituted $\mathrm{LaCoO}_{3}$ with both variable oxidation state of cobalt between +2 and +3 $\left(\mathrm{La}_{2} \mathrm{Co}\left(\mathrm{Ti}_{1-x} \mathrm{Mg}_{x}\right) \mathrm{O}_{6}, 0 \leq x \leq 0.5\right)$ and variable $\mathrm{Co}^{3+}$-content relative to the other $\mathrm{B}$-cations $\left(\mathrm{La}_{2} \mathrm{Co}_{1+z}\left(\mathrm{Ti}_{0.5} \mathrm{Mg}_{0.5}\right)_{1-z} \mathrm{O}_{6}, 0.2 \leq z \leq 0.6\right)$ have been investigated. Based on the temperature dependence of the thermal expansion, electronic transport properties and Seebeck coefficient, three different groups of compositions according to their symmetries can be allocated. It was found that the thermal expansion coefficients (TECs) of the studied compounds are mainly dependent on the proportion of $\mathrm{Co}^{2+} / \mathrm{Co}^{3+}$. For $\mathrm{La}_{2} \mathrm{Co}\left(\mathrm{Ti}_{1-x} \mathrm{Mg}_{x}\right) \mathrm{O}_{6}$, the TEC increases from $9(x=0)$ to $\sim 19 \mathrm{ppmK}^{-1}(x=0.5)$ with an increase of the oxidation state of cobalt from +2 and +3 , respectively. The TECs of $\mathrm{La}_{2} \mathrm{Co}_{1+z}\left(\mathrm{Ti}_{0.5} \mathrm{Mg}_{0.5}\right)_{1-z} \mathrm{O}_{6}, z=0.2-0.6$ with $\mathrm{Co}^{3+}$-only, remains constant at $\sim 21 \mathrm{ppmK}^{-1}$ independently of the cobalt content. Thermoelectric measurements of the system indicates that all samples in the system, except $\mathrm{La}_{2} \mathrm{Co}_{1.6}\left(\mathrm{Ti}_{0.5} \mathrm{Mg}_{0.5}\right)_{0.4} \mathrm{O}_{6}$, are $p$ type conductors over the whole temperature range, $300<T<1175 \mathrm{~K}$. The conductivities were found to increase with an increase of both $\mathrm{Co}^{3+}$ and total cobalt content and are described with a small polaron hopping model. Due to an insignificant number of oxygen vacancies of $\mathrm{La}_{2} \mathrm{Co}_{1+z}\left(\mathrm{Ti}_{1-x} \mathrm{Mg}_{x}\right)_{1-z} \mathrm{O}_{6}$ samples prepared in air at elevated temperatures, the investigated system is proposed as an excellent model system for the investigation of influences of Co oxidation state and stoichiometry on different properties in perovskite cobalt oxides.

Keywords: Perovskite, Cobaltate, Thermal expansion, Seebeck, Electronic conductivity, Magnetic susceptibility 


\section{Introduction}

The perovskite type cobaltate $\mathrm{LaCoO}_{3}$ (LCO) has been the object of many studies ${ }^{1-6}$ due to its complex magnetic and electronic transport properties caused by transitions between different spin states of $\mathrm{Co}^{3+}$. For example, $\mathrm{LaCoO}_{3}$ undergoes a spin-state transition from low spin (LS, $\mathrm{t}_{2 \mathrm{~g}}{ }^{6} \mathrm{e}_{\mathrm{g}}{ }^{0}$ ) to high spin (HS, $\mathrm{t}_{2 \mathrm{~g}}{ }^{4} \mathrm{e}_{\mathrm{g}}{ }^{2}$ ) at about $100 \mathrm{~K}$ leading to a change from a diamagnetic to a paramagnetic behaviour. Above $500 \mathrm{~K}$ its conductivity transcends from a semiconducting to a metallic conductivity. Starting from theoretical work of Korotin et al. ${ }^{7}$ in which a stabilization of an excited intermediate spin state (IS, $\mathrm{t}_{2 \mathrm{~g}}{ }^{5} \mathrm{e}_{\mathrm{g}}{ }^{1}$ ) was proposed, a number of studies claiming the presence of IS $\mathrm{Co}^{3+}$ in $\mathrm{LaCoO}_{3}$ are found in the literature. However, the existence of IS $\mathrm{Co}^{3+}$ in perovskite-related cobaltates is still under debate, e.g. X-ray absorption spectroscopy shows only LS and $\mathrm{HS} \mathrm{Co}^{3+}$ in $\mathrm{LaCoO}_{3}$ up to $650 \mathrm{~K}^{8}{ }^{8}$ Temperatureinduced spin state transitions of $\mathrm{Co}^{3+}$ resulted in high thermal expansion coefficients (TEC) of cobaltites (e.g. $\mathrm{TEC}_{\mathrm{LaCoO}_{3}} \approx 21 \mathrm{ppm} / \mathrm{K}{ }^{9,10}$ ) and significantly hamper their use in various hightemperature electrochemical devices. Therefore, it is of great interest to study the influence of the oxidation state of cobalt on high-temperature thermal expansion and electronic conductivity properties of Co-containing perovskites.

Recently, we have reported on the phase formation and structural characterization of perovskite phases in the system $\mathrm{La}_{2} \mathrm{Co}_{1+z}\left(\mathrm{Ti}_{1-x} \mathrm{Mg}_{x}\right)_{1-z} \mathrm{O}_{6}(0 \leq x \leq 1,0 \leq z \leq 1)$. ${ }^{11}$ For $\mathrm{La}_{2} \mathrm{Co}\left(\mathrm{Ti}_{1-x} \mathrm{Mg}_{x}\right) \mathrm{O}_{6}(0 \leq x \leq 0.6)$ being compounds with fixed cobalt content, the formal Co oxidation state is changed from +2 to +3.2 with a substitution of $\mathrm{Ti}^{4+}$ by $\mathrm{Mg}^{2+}$. The symmetry of the perovskite phase in the system changes from monoclinic $\left(P 2_{1} / n\right)$ for $0 \leq x \leq 0.2$, via orthorhombic (Pnma) $(0.3 \leq x \leq 0.4)$ to rhombohedral $(R 3 c)(0.5 \leq x \leq 0.6)$. Rhombohedral perovskites $\mathrm{La}_{2} \mathrm{Co}_{1+z}\left(\mathrm{Ti}_{0.5} \mathrm{Mg}_{0.5}\right)_{1-z} \mathrm{O}_{6}(0 \leq z \leq 0.6)$ with a fixed formal oxidation state of +3 for $\mathrm{Co}$ and a Co concentration at the $B$ site between 50 and $80 \%$ were also synthesised. In this study, we present high temperature properties of these compounds; i.e. thermal expansion, electronic conductivity, Seebeck coefficient and magnetic susceptibility. We discuss how these properties correlate with structure, oxidation state of cobalt and absolute amount of cobalt.

\section{Experimental}

\subsection{Synthesis}

Samples in the $\mathrm{La}_{2} \mathrm{Co}_{1+z}\left(\mathrm{Ti}_{1-x} \mathrm{Mg}_{x}\right)_{1-z} \mathrm{O}_{6}(z=0$ and $0 \leq x \leq 0.5$, step $=0.1 ; x=0.5$ and $0 \leq z \leq$ 0.6 , step $=0.2$ ), system were synthesized by the citric-acid route. The starting materials, i.e. 
$\mathrm{La}_{2} \mathrm{O}_{3}$ (Aldrich, $99.99 \%$ ), $\mathrm{MgO}$ (Merck, analytical grade) (both powders were pre-dried at $1223 \mathrm{~K}$ for $24 \mathrm{~h}$ ) cobalt(II)acetate tetra hydrate (Sigma-Aldrich, reagent grade) and titanium(IV)butoxide (Sigma-Aldrich, $97.0 \mathrm{wt} \%$ ) were dissolved in stoichiometric amounts in concentrated nitric acid with anhydrous citric acid (Merck, 99\%) as a complex binder, to get a well dispersed mixing of the elements in the precursor gel. More details about the synthesis is described in reference ${ }^{11}$. The gels were calcinated at $1173 \mathrm{~K}$ in air for $2 \mathrm{~h}$. The samples were annealed in air at a final temperature of $1623 \mathrm{~K}$ for $24 \mathrm{~h}$ with intermediate grindings.

\subsection{Characterization}

\subsubsection{Thermal expansion}

Linear thermal expansion measurements were made on a Netzsch DIL 402C dilatometer calibrated with a sapphire sample as a standard. Oxide powders were pressed into pellets 8 $\mathrm{mm}$ in diameter and $5-5.5 \mathrm{~mm}$ height and sintered at $1623 \mathrm{~K}$ for $24 \mathrm{~h}$ in air and polished to approximately the same size as the sapphire standard. Measurements were performed in air from room temperature (RT) up to $1273 \mathrm{~K}$, at a heating rate of $5 \mathrm{~K} / \mathrm{min}$.

\subsubsection{High-temperature determination of Seebeck coefficient and electronic conductivity measurements}

High-temperature Seebeck coefficient and electronic conductivity were measured in synthetic air atmosphere from RT up to $1173 \mathrm{~K}$ with an Ozawa Science RZ2001i measurement system. The presented measurements were restricted to the reliable measurement range of electrical resistivities between $10^{-7}-10^{4} \Omega \mathrm{m}$. Electronic conductivity was measured using the fourpoint probe method, while the Seebeck coefficient was measured in steady-state mode. Samples were prepared in the form of rectangular bars with dimensions $2 \mathrm{~mm} \times 2 \mathrm{~mm} \times 13$ $\mathrm{mm}$ and sintered once more using the same program as with the initial synthesis.

\subsubsection{High temperature magnetic properties}

Temperature dependence measurements of the magnetic moment in the temperature range RT-800 K at an applied magnetic field of $1 \mathrm{~T}$ of the pressed powder samples of $\mathrm{La}_{2} \mathrm{Co}_{1+z}\left(\mathrm{Ti}_{1-}\right.$ $\left.{ }_{x} \mathrm{Mg}_{x}\right)_{1-z} \mathrm{O}_{6}$ were performed using a MPMS SQUID magnetometer (Quantum Design).

\section{Results}

\subsection{Thermal expansion}

Thermal expansion curves, from RT up to $1273 \mathrm{~K}$, for $\mathrm{La}_{2} \mathrm{Co}\left(\mathrm{Ti}_{1-x} \mathrm{Mg}_{x}\right) \mathrm{O}_{6}(0 \leq x \leq 0.5)$ and $\mathrm{La}_{2} \mathrm{Co}_{1+z}\left(\mathrm{Ti}_{0.5} \mathrm{Mg}_{0.5}\right)_{1-z} \mathrm{O}_{6}(0 \leq z \leq 0.6)$ are shown in FIG. 1a and $1 \mathrm{~b}$, respectively. Only the 
$\mathrm{La}_{2} \mathrm{CoTiO}_{6}(x=0)$ sample, nominally containing only $\mathrm{Co}^{2+}$, expands linearly with temperature. For all other samples, the curves are sigmoidal with increasing of TEC with temperature. For $\mathrm{La}_{2} \mathrm{Co}_{1+z}\left(\mathrm{Ti}_{0.5} \mathrm{Mg}_{0.5}\right)_{1-z} \mathrm{O}_{6}(0 \leq z \leq 0.6)$ samples (see FIG. 1b) the curves have similar shapes and are practically identical for $z=0.2,0.4$ and 0.6. The average TEC calculated between $T=298$ and $1173 \mathrm{~K}$ is given in FIG. 2 .

FIG. 1 Linear thermal expansion for (a) $\mathrm{La}_{2} \mathrm{Co}\left(\mathrm{Ti}_{1-x} \mathrm{Mg}_{x}\right) \mathrm{O}_{6}(0 \leq x \leq 0.5)$ and (b) $\mathrm{La}_{2} \mathrm{Co}_{1+z}\left(\mathrm{Ti}_{0.5} \mathrm{Mg}_{0.5}\right)_{1-z} \mathrm{O}_{6}$ $(0 \leq z \leq 0.6)$. The bottom curve corresponds to $x=0$ and $z=0$ in FIG. 1 a and $b$ respectively, thereafter they follow with increasing values to the uppermost curve with the $x$ and $z$ values.

FIG. 2 Average linear thermal expansion coefficient (TEC) at temperatures 298 - $1273 \mathrm{~K}$ (left) for $\mathrm{La}_{2} \mathrm{Co}\left(\mathrm{Ti}_{1-\mathrm{x}} \mathrm{Mg}_{\mathrm{x}}\right) \mathrm{O}_{6}$ as a function of $\mathrm{x}$ and (right) for $\mathrm{La}_{2} \mathrm{Co}_{1+\mathrm{z}}\left(\mathrm{Ti}_{0.5} \mathrm{Mg}_{0.5}\right)_{1-\mathrm{z}} \mathrm{O}_{6}$ as a function of $1+\mathrm{z}$. The value for $\mathrm{LaCoO}_{3}$ has been inserted as reference (black square). ${ }^{12}$

\subsection{High temperature electronic conductivity}

The temperature dependence of the d.c. electronic conductivity between RT and $1173 \mathrm{~K}$ were measured in synthetic air, both for $\mathrm{La}_{2} \mathrm{Co}\left(\mathrm{Ti}_{1-x} \mathrm{Mg}_{x}\right) \mathrm{O}_{6}(0 \leq x \leq 0.5)$ and $\mathrm{La}_{2} \mathrm{Co}_{1+z}\left(\mathrm{Ti}_{0.5} \mathrm{Mg}_{0.5}\right)_{1-z} \mathrm{O}_{6}(0 \leq z \leq 0.6)$. All samples show an increase in conductivity $(\sigma)$ with increasing temperature. The conductivity increases also with the increase of the $\mathrm{Co}^{3+}$ content for $\mathrm{La}_{2} \mathrm{Co}\left(\mathrm{Ti}_{1-x} \mathrm{Mg}_{x}\right) \mathrm{O}_{6}(0 \leq x \leq 0.5)$ and with the increase of the total amount of $\mathrm{Co}^{3+}$ for $\mathrm{La}_{2} \mathrm{Co}_{1+z}\left(\mathrm{Ti}_{0.5} \mathrm{Mg}_{0.5}\right)_{1-z} \mathrm{O}_{6}(0 \leq z \leq 0.6)$. The graphs of $\log (\sigma T) v s .1 / T$ for the studied samples are shown in FIG. 3. For $x=0.0$ and 0.1, a smooth, nearly linear Arrhenius-type behaviour is observed. For $\mathrm{La}_{2} \mathrm{Co}\left(\mathrm{Ti}_{1-x} \mathrm{Mg}_{x}\right) \mathrm{O}_{6}$ with an increase of the $\mathrm{Co}^{3+}$ content $(x)$, the slope of the curves start to decrease at higher temperatures, $T>673 \mathrm{~K}$, indicating a decrease in the activation energy. This behaviour becomes even more pronounced and shifted towards lower temperatures for $\mathrm{La}_{2} \mathrm{Co}_{1+z}\left(\mathrm{Ti}_{0.5} \mathrm{Mg}_{0.5}\right)_{1-z} \mathrm{O}_{6}(0 \leq z \leq 0.6)$ containing only $\mathrm{Co}^{3+}$.

FIG. 3 Arrhenius plot of the high temperature electronic conductivity data $\log (\sigma T)$ vs. $1 / T$ of $\operatorname{La} a_{2} \operatorname{Co}\left(\operatorname{Ti}_{1-}\right.$ $\left.{ }_{x} \mathrm{Mg}_{x}\right) \mathrm{O}_{6}(0 \leq x \leq 0.5)$ and $\mathrm{La}_{2} \mathrm{Co}_{1+z}\left(\mathrm{Ti}_{0.5} \mathrm{Mg}_{0.5}\right)_{1-z} \mathrm{O}_{6}(0 \leq z \leq 0.6)$

The semiconductor-like behaviour of these samples and the results from XANES measurements ${ }^{11}$ indicate that the cobalt ions exist in two discrete oxidation states, i.e. +2 and +3 , and suggest that the electronic conduction in these samples can be described in terms of small polaron hopping model. The activation energies for the conduction have been derived from the nearly linear regions between 473-873 K using the Arrhenius like equation modified for small polarons: 


$$
\sigma=\frac{\sigma_{0}}{T} e^{-\frac{E_{\sigma}}{k_{B} T}}
$$

where $\sigma$ is the electronic conductivity, $T$ the absolute temperature, $k_{B}$ Boltzmann's constant, $\sigma_{0}$ a pre-exponential factor containing information about the charge carrier concentration and their mobility and $E_{\sigma}$ the activation energy. Calculated values of $E_{\sigma}$ and conductivity $\sigma$ of the samples at $T=1173 \mathrm{~K}$ for $\mathrm{La}_{2} \mathrm{Co}\left(\mathrm{Ti}_{1-x} \mathrm{Mg}_{x}\right) \mathrm{O}_{6}$ and $\mathrm{La}_{2} \mathrm{Co}_{1+z}\left(\mathrm{Ti}_{0.5} \mathrm{Mg}_{0.5}\right)_{1-z} \mathrm{O}_{6}$ are shown in FIG. 4. The activation energies for the electronic conductivity lies around $0.5 \mathrm{eV}$ for $\mathrm{Co}^{2+}$ rich compositions ( $x=0.0$ and 0.1 ), while a significant higher value $\sim 0.65 \mathrm{eV}$ is observed for $x=0.2$, whereafter it decreases to $\sim 0.45 \mathrm{eV}$ for $x=0.5$. The increase of the total amount $\mathrm{Co}^{3+}$ at the $B$-site along the $z$-line, decreases the activation energy towards $\mathrm{E}_{\sigma} \approx 0.25 \mathrm{eV}$ as reported for $\mathrm{LaCoO}_{3}$ between $373-1273 \mathrm{~K}^{13}$

FIG. 4 The variation of the electronic conductivity at $T=1173 \mathrm{~K}$ (green symbols) and the corresponding activation energies (red symbols) for the compositions $\mathrm{La}_{2} \mathrm{Co}\left(\mathrm{Ti}_{1-x} \mathrm{Mg}_{x}\right) \mathrm{O}_{6}(0 \leq x \leq 0.5)$ and $\mathrm{La}_{2} \mathrm{Co}_{1+z}\left(\mathrm{Ti}_{0.5} \mathrm{Mg}_{0.5}\right)_{1-z} \mathrm{O}_{6}(0 \leq z \leq 0.6)$

\subsection{Seebeck coefficient measurements}

The Seebeck coefficients, $S(\mu \mathrm{V} / \mathrm{K})$ were measured between RT and $1173 \mathrm{~K}$ in synthetic air for the samples $\mathrm{La}_{2} \mathrm{Co}\left(\mathrm{Ti}_{1-x} \mathrm{Mg}_{x}\right) \mathrm{O}_{6}(0 \leq x \leq 0.5)$ and $\mathrm{La}_{2} \mathrm{Co}_{1+z}\left(\mathrm{Ti}_{0.5} \mathrm{Mg}_{0.5}\right)_{1-z} \mathrm{O}_{6}(0 \leq z \leq 0.6)$ as shown in FIG. 5. The Seebeck coefficients for all the $\mathrm{La}_{2} \mathrm{Co}\left(\mathrm{Ti}_{1-x} \mathrm{Mg}_{x}\right) \mathrm{O}_{6}$ samples with a variable nominal oxidation state of cobalt are positive with $S>100 \mu \mathrm{V} / \mathrm{K}$ at all temperatures measured, which is typical for a small polaron conductor. ${ }^{14}$ The positive sign indicates that holes are the major charge carriers. For all studied compositions the temperature dependence of the Seebeck coefficient stabilises or even converges to an approximately constant value at higher temperatures. Such a phenomenon is common in systems where a charge disproportionation takes place; i.e. $2 \mathrm{Co}^{3+} \rightarrow \mathrm{Co}^{2+}+\mathrm{Co}^{4+}$. ${ }^{13}$ Selecting a conduction model assuming small polarons as charge carriers can be supported by quantifying the heat of charge carrier jump $H_{ \pm}$(unit in $\left.\mathrm{eV}\right)^{15}$ for the different composition, which can be calculated from $H_{ \pm}=$ $E_{\sigma}-E_{S}$. The energy of polaron ionization $E_{S}$ is calculated from the Seebeck coefficient according to the formula ${ }^{16}$

$$
S= \pm \frac{k_{B}}{e}\left(\frac{E_{S}}{k_{B} T}+B\right)
$$

where $E_{S}$ is the energy of polaron ionization, $e$ the charge of the electron and $B$ an entropy term for the charge transfer (where $E_{\sigma}$ is the activation energy from the electronic 
conductivity measurements discussed above). A $H_{ \pm} \neq 0$ is an indication of thermally activated charge transfer of "jumping" localized electrons/holes, i.e. small-radius polarons, while with $H_{ \pm} \approx 0$ the charge transfer is more metallic; i.e. by large-radius polarons, with zero/very low activation energy. ${ }^{15}$ The Seebeck coefficients $v s .1 / T$ are shown in FIG. 6. The values for $E_{S}$ are calculated using the linear part in the temperature range $623 \leq T \leq 1143 \mathrm{~K}$ in FIG. 6 shown in FIG. 7. The heat of charge transfer jump calculated as $H_{ \pm}=E_{\sigma}-E_{S}$ is presented in FIG. 8. The observed values are up to a magnitude larger than reported for $\mathrm{LaCoO}_{3} \sim 0.07-$ $0.085 \mathrm{eV}^{15}$, thus in agreement with a small polaron model.

FIG. 5 Seebeck coefficients $v s$. $T$, measured from RT to $1173 \mathrm{~K}$ in air, of $\left.\operatorname{La}_{2} \mathrm{Co}_{\left(1 i_{1-x}\right.} \mathrm{Mg}_{x}\right) \mathrm{O}_{6}(0 \leq x \leq 0.5)$ and $\mathrm{La}_{2} \mathrm{Co}_{1+z}\left(\mathrm{Ti}_{0.5} \mathrm{Mg}_{0.5}\right)_{1-z} \mathrm{O}_{6}(0 \leq z \leq 0.6)$.

FIG. 6 Seebeck coefficients $v s .1 / T$, measured from RT to $1173 \mathrm{~K}$ in air, of $\left.\operatorname{La}_{2} \operatorname{Co}_{\left(1 i_{1-x}\right.} \mathrm{Mg}_{x}\right) \mathrm{O}_{6}(0 \leq x \leq 0.5)$ and $\mathrm{La}_{2} \mathrm{Co}_{1+z}\left(\mathrm{Ti}_{0.5} \mathrm{Mg}_{0.5}\right)_{1-z} \mathrm{O}_{6}(0 \leq z \leq 0.6)$. A linear Arrhenius behaviour is observed in the temperature range $\sim 643-1143 \mathrm{~K}$.

FIG. 7 Corresponding values for the energy of polaron ionization $\left(E_{S}\right)$ calculated from the Seebeck coefficients $v s .1 / T$ in the linear temperature range $\sim 643-1143 \mathrm{~K}_{\text {for }} \operatorname{La}_{2} \mathrm{Co}\left(\mathrm{Ti}_{1-x} \mathrm{Mg}_{x}\right) \mathrm{O}_{6}(0 \leq x \leq 0.5)$ and $\mathrm{La}_{2} \mathrm{Co}_{1+z}\left(\mathrm{Ti}_{0.5} \mathrm{Mg}_{0.5}\right)_{1-z} \mathrm{O}_{6}(0 \leq z \leq 0.6)$

FIG. 8 Compositional variation of the heats of charge carrier jump, $\mathrm{H}_{ \pm}(\mathrm{eV})$. The value for $\mathrm{LaCoO}_{3}$ has been inserted as a reference (black triangle). ${ }^{15}$

\subsection{High temperature magnetic properties}

The high temperature magnetic susceptibilities were measured in air between $300-800 \mathrm{~K}$ for the $\mathrm{La}_{2} \mathrm{Co}\left(\mathrm{Ti}_{1-x} \mathrm{Mg}_{x}\right) \mathrm{O}_{6}, x=0.0,0.2,0.5$ samples in order to follow the changes in magnetic moment $\left(\mu_{\text {eff }}\right)$ for Co in the nominal oxidation states $+2,+2.4$ and +3 , as shown in FIG. 9 and 10. The $x=0.0$ and 0.2 samples exhibit a Curie-Weiss law behaviour over the whole measured temperature range while the $x=0.5$ sample does not. The calculated magnetic moments from the Curie-Weiss law for $x=0.0$ and $x=0.2$ are 4.02 and 3.96 B.M, respectively. The value for $x=0.0$ sample is close to the expected magnetic moments for $\mathrm{Co}^{2+}$ (HS) (3.87 B.M.). A lower value for the $x=0.2$ sample indicates that some amount of $\mathrm{Co}^{3+}$ cations are in LS state. Taking into account spin-only values for $\mathrm{Co}^{2+}(\mathrm{HS})$ and $\mathrm{Co}^{3+}$ (HS) and (LS) one can estimate that $\sim 84 \%$ of $\mathrm{Co}^{3+}$ are in HS state. The calculated $\mu_{\text {eff }}$ for $x=0.5$ increases with temperature from 2.0 B.M. at $300 \mathrm{~K}$ to $c a .2 .8$ B.M. at $800 \mathrm{~K}$ indicating an increase of the amount $\mathrm{HS} \mathrm{Co}^{3+}$ at the expense of $\mathrm{LS} \mathrm{Co}^{3+}$. It should be noted that the $\mu_{\text {eff }}$ value at $800 \mathrm{~K}$ corresponds to $\sim 57 \%$ while the $\mu_{\text {eff }}$ value at $300 \mathrm{~K}$ corresponds to $\sim 40 \% \mathrm{HS}$ $\mathrm{Co}^{3+}$. 
FIG. 9 Temperature dependence of inverse magnetic susceptibilities $\left(\chi^{-1}\right)$ for $\operatorname{La}_{2} \mathrm{Co}\left(\operatorname{Ti}_{1-x} \mathrm{Mg}_{x}\right) \mathrm{O}_{6}, x=0.0,0.2$ and 0.5 samples.

FIG. 10 Temperature dependence of the calculated magnetic moments $\left(\mu_{\mathrm{eff}}\right)$ for $\operatorname{La}_{2} \operatorname{Co}\left(\operatorname{Ti}_{1-\mathrm{x}} \mathrm{Mg}_{\mathrm{x}}\right) \mathrm{O}_{6}, \mathrm{x}=0.0$, 0.2 and 0.5 samples.

\section{Discussion}

The number of studies on the correlations between cobalt oxidation state and various hightemperature properties of cobalt-based perovskites is quite limited, probably due to difficulties to control the compositions. For example, $A$-site substituted ( $A=$ alkaline-earth cation) $\mathrm{LaCoO}_{3}$ is not suitable for such studies since the oxygen content of the perovskites $\mathrm{La}_{1-x} A_{x} \mathrm{CoO}_{3-y}$ is changing both with composition ( $x$ ) and temperature. ${ }^{10,17} B$-site substituted $\mathrm{LaCoO}_{3}$ compounds are better suited, but only when the $B$ cation is in a stable oxidation state e.g. $\mathrm{Mg}^{2+}, \mathrm{Sc}^{3+}, \mathrm{Ti}^{4+}$, since it otherwise can result into an uncertainty in the oxidation state of the cobalt atoms. Therefore, the best systems seem to be the $B$-site substituted $\mathrm{LaCoO}_{3}$, with $B$ cations $\left(\mathrm{M}^{2+}\right.$ or $\left.\mathrm{M}^{4+}\right)$ having stable oxidation states. Taking into account appropriate sizes of $B$ cations, $\mathrm{Mg}^{2+}$ and $\mathrm{Ti}^{4+}$ can be used to tune the oxidation state of the cobalt. Substitution of $\mathrm{Co}^{3+}$ by $\mathrm{Mg}^{2+}$ formally leads to a partial oxidation of $\mathrm{Co}^{3+}$ towards $\mathrm{Co}^{4+}$, while $\mathrm{Ti}^{4+}$ leads to a partial reduction towards $\mathrm{Co}^{2+}$. Such compounds like $\mathrm{LaCo}_{1-x} \mathrm{Mg}_{x} \mathrm{O}_{3}$ (LCMO) and $\mathrm{LaCo}_{1-x} \mathrm{Ti}_{x} \mathrm{O}_{3}$ (LCTO) are known, although, the former one has a quite limited homogeneity range, $x \leq 0.1^{1}$. The substitution of $\mathrm{Co}^{3+}$ by $\mathrm{Mg}^{2+}$, with a simultaneous formation of $\mathrm{Co}^{4+}$, leads to the introduction of holes accompanied by a considerable decrease of the activation energy for the electronic conductivity, due to the introduction of holes, similar to what has been observed upon substitution of $\mathrm{La}^{3+}$ by $\mathrm{Sr}^{2+}$ in $\mathrm{La}_{1-x} \mathrm{Sr}_{x} \mathrm{CoO}_{3}{ }^{18}$ This is reflected as a decreasing positive ( $p$-type conductivity) Seebeck coefficient with increasing $\mathrm{Mg}^{2+}$ content. ${ }^{1}$ When it comes to substitution of $\mathrm{Co}^{3+}$ by $\mathrm{Ti}^{4+}$ in LCTO, several studies ${ }^{1,2,19,20}$ have shown that it is possible to substitute up to an $x$ value of 0.5 , corresponding to the presence of $\mathrm{Co}^{2+}$ ions only. The conductivity for LCTO decreases with $x$, but changes first from $p$-type for $\mathrm{LaCoO}_{3}$ to $n$-type, and then later back to $p$-type when $x$ exceeds 0.1 . This unexpected behaviour has been attributed to a decrease in electron mobility due to a trapping of electrons in $\mathrm{Ti}^{4+}-\mathrm{O}-\mathrm{Co}^{2+}$ clusters. ${ }^{1}$ It can be added here, that TEC:s have not been determined for the LCTO and LCMO systems to the present date, although it might be of interest, when investigating the effects of a varying oxidation state of $\mathrm{Co}$. However, for $\mathrm{LaCo}_{1-x} M_{x} \mathrm{O}_{3}$ the cobalt content changes with $M$ cation content (x) making it difficult to distinguish between effects on the electronic transport properties caused by changes in cobalt oxidation state from 
those caused by changes in cobalt content. For the LCMO system the formation of oxygen vacancies upon $\mathrm{Mg}^{2+}$ substitution is an additional complexity. ${ }^{1}$

Compounds in the system $\mathrm{La}_{2} \mathrm{Co}_{1+z}\left(\mathrm{Ti}_{1-x} \mathrm{Mg}_{\mathrm{x}}\right)_{1-z} \mathrm{O}_{6}$ are excellent candidates for studying correlations between cobalt oxidation state and various high-temperature properties. One of the reason for this is that the oxygen content of $\mathrm{La}_{2} \mathrm{Co}\left(\mathrm{Ti}_{1-x} \mathrm{Mg}_{x}\right) \mathrm{O}_{6}$ remains unchanged up to high-temperature regions. This conclusion is supported by the absence of weight change of $\mathrm{La}_{2} \mathrm{Co}\left(\mathrm{Ti}_{0.5} \mathrm{Mg}_{0.5}\right) \mathrm{O}_{6}$ sample in thermogravimetric experiment in vacuum $\left(\sim 10^{-3}\right.$ bar $)$ up to $1273 \mathrm{~K}$. However, during high temperature measurements of the magnetic susceptibilities in a PPMS instrument under high vacuum $\left(10^{-8}\right.$ bar), hysteresis effects were observed for the heating and cooling curves of the magnetic susceptibility. After such measurements, the Xray powder diffraction patterns of the $x=0.5$ with $z=0.2$ sample resulted in a significant shift in the unit cell parameters, which changed back to the original values after heating in air at $973 \mathrm{~K}$. This shows that in air, at least for $\mathrm{La}_{2} \mathrm{Co}\left(\mathrm{Ti}_{1-x} \mathrm{Mg}_{x}\right) \mathrm{O}_{6}$, one can exclude the effect of the so-called chemical factor, associated with the formation of oxygen vacancies at high temperatures, which has an influence on both transport and thermal expansion properties of oxides. The absence of oxygen vacancies in such type of cobaltites can also be supported by the results of the recent study of $\mathrm{La}_{2-\mathrm{x}} \mathrm{Sr}_{\mathrm{x}} \mathrm{CoTiO}_{6}, 0 \leq \mathrm{x} \leq 1.0$, where the authors did not observe the deviation from oxygen stoichiometry for the whole compositional range in air atmosphere. ${ }^{21}$ The probability of oxygen vacancies at elevated temperatures for the Co-rich compositions $\mathrm{La}_{2} \mathrm{Co}_{1+z}\left(\mathrm{Ti}_{0.5} \mathrm{Mg}_{0.5}\right)_{1-z} \mathrm{O}_{6}, z=0.2,0.4$ and 0.6 , like in the case of $\mathrm{LaCoO}_{3}{ }^{22,23}$, is significantly higher, of course. However, there were no indications of the formation of oxygen vacancies in the compounds under the studied experimental conditions.

Based on obtained results of high-temperature properties measurements of $\mathrm{La}_{2} \mathrm{Co}_{1+z}\left(\mathrm{Ti}_{1-x} \mathrm{Mg}_{x}\right)_{1-z} \mathrm{O}_{6}$ samples, like thermal expansion, electronic conductivity, and Seebeck coefficient, the samples gather in 3 different groups of behaviour. The first group includes the $\mathrm{La}_{2} \mathrm{Co}\left(\mathrm{Ti}_{1-x} \mathrm{Mg}_{x}\right) \mathrm{O}_{6}, x=0.0$ and 0.1 samples, which differ compared to the other compositions in their thermal expansion behaviour and electronic conductivity properties (see FIG. 1, 4 and 5). This is due to the fact that $x=0.0$ and 0.1 samples have the highest amount of $\mathrm{Co}^{2+}$ and, more importantly, Ti and Co are ordered in their crystal structures. ${ }^{11}$ It should be mentioned here, that the $B$-cation ordering is also found for the $x=0.2$ sample, however, the ordering is weaker than for $x=0.0$ and 0.1 as judged from the SAED patterns and the Néel temperature $\left(T_{N}(x=0.2) \approx 8 \mathrm{~K}\right.$ compared to $T_{N}(x=0.1) \approx 15 \mathrm{~K}{ }^{11}$ The second 
group includes $\mathrm{La}_{2} \mathrm{Co}\left(\mathrm{Ti}_{1-x} \mathrm{Mg}_{x}\right) \mathrm{O}_{6}, x=0.2-0.4$ samples, where the lattice symmetry changes from monoclinic to orthorhombic with increasing $x$, the latter with complete disorder of the $B$ cations. The third group includes compositions $\mathrm{La}_{2} \mathrm{Co}_{1+z}\left(\mathrm{Ti}_{0.5} \mathrm{Mg}_{0.5}\right)_{1-z} \mathrm{O}_{6}, z=0.2-0.6$ with only $\mathrm{Co}^{3+}$. The composition $\mathrm{La}_{2} \mathrm{Co}\left(\mathrm{Ti}_{0.5} \mathrm{Mg}_{0.5}\right) \mathrm{O}_{6}$ is difficult to appoint to the second or the third group. According to thermal expansion and high-temperature conductivity behaviour it belongs to the second group, while according to Seebeck coefficient measurements it is better to refer it to the third group.

In the discussion one should also remember that the XANES studies suggest that cobalt exists in two discrete oxidation states i.e. $\mathrm{Co}^{2+}$ and $\mathrm{Co}^{3+}$. To understand high-temperature properties of the compounds in such systems it is necessary to take into account transitions between LS and HS states of $\mathrm{Co}^{3+}$ as well as the disproportionation of $\mathrm{Co}^{3+}$ to $\mathrm{Co}^{4+}$ and $\mathrm{Co}^{2+}$. We will not involve the possibility of IS $\mathrm{Co}^{3+}$ in our discussions as it is not necessary and the presented results do not add anything to the ongoing discussion in literature on whether IS $\mathrm{Co}^{3+}$ exists or not in cobalt-based perovskites.

\section{Thermal expansion coefficients}

The major contribution to the increasing average TEC of $\mathrm{La}_{2} \mathrm{Co}\left(\mathrm{Ti}_{1-\mathrm{x}} \mathrm{Mg}_{\mathrm{x}}\right) \mathrm{O}_{6}$ with $x$, seems to originate from the formation of $\mathrm{Co}^{3+}$ ions when $\mathrm{Mg}^{2+}$ is introduced, since the number of oxygen vacancies are negligible and the structural changes are not drastic. One may therefore expect that the main contribution to the thermal expansion comes from transitions between different spin states of $\mathrm{Co}^{3+}$.

The thermal expansion curve for the sample with composition $x=0.0$, with $\mathrm{HS} \mathrm{Co}^{2+}$ shown in FIG. 1, follows a straight line, as anticipated from a material where the main expansion comes from thermal vibrations. This composition can therefore be considered as the baseline for the thermal expansion of the compounds. When the $\mathrm{Co}^{3+}$ content in $\mathrm{La}_{2} \mathrm{Co}\left(\mathrm{Ti}_{1-x} \mathrm{Mg}_{x}\right) \mathrm{O}_{6}$ increases with increasing $x$, the linear relation between thermal expansion and temperature disappears and the curves starts to bend upwards at high temperatures, as seen in FIG. 1. This nonlinearity can be explained by spin-transitions of LS to HS $\mathrm{Co}^{3+}$. The average TEC calculated between $T=298$ and $1273 \mathrm{~K}$ increases fairly linearly with increasing $x$, i.e. with increasing relative content of $\mathrm{Co}^{3+}$, from $\sim 9 \mathrm{ppm} / \mathrm{K}$ for $x=0.0$ to $\sim 19 \mathrm{ppm} / \mathrm{K}$ for $x=0.5$, as shown in Fig. 3. The TEC values ( $c a .21 \mathrm{ppm} / \mathrm{K}$ ) for $\mathrm{La}_{2} \mathrm{Co}_{1+z}\left(\mathrm{Ti}_{0.5} \mathrm{Mg}_{0.5}\right)_{1-z} \mathrm{O}_{6}, z=0.2,0.4$ and 0.6 with Co oxidation state $3+$ only, are slightly higher than for the sample with $z=0.0(c a .19 \mathrm{ppm} / \mathrm{K})$ and close to the value $21 \mathrm{ppm} / \mathrm{K}^{24}$ reported for $\mathrm{LaCoO}_{3}$ c.f. Fig. 3. 
The increase in TEC from $x=0.0$ to $x=0.3$ is an order of magnitude smaller than what is observed for $x>0.3$. This can be explained by taking into account the different proportions of LS and $\mathrm{HS} \mathrm{Co}^{3+}$ in the samples with different $\mathrm{Mg}^{2+}$ content. The XANES measurements showed that the LS/HS ratio increases as the $x$-value increases. ${ }^{11}$ A stabilization of LS $\mathrm{Co}^{3+}$ with an increase of the $\mathrm{Mg}^{2+}$ amount can easily be explained by the so called chemical pressure effects, which is caused by the presence of the larger $\mathrm{Mg}^{2+}$ neighbouring the $\mathrm{Co}^{3+}$ cations. It resembles the situation with the spin blockade phenomenon which takes place in $\mathrm{La}_{1.5} \mathrm{Sr}_{0.5} \mathrm{CoO}_{4}$, where ordering of large $\mathrm{Co}^{2+}$ (HS) and $\mathrm{Co}^{3+}$ causes the latter to stabilize in a LS state with smaller ionic radius ${ }^{25}$ Therefore, one can expect an increasing amount of LS $\mathrm{Co}^{3+}$ with increasing magnesium content, leading to an accelerating effect of $\mathrm{Co}^{3+} \mathrm{LS} / \mathrm{HS}$ spin transitions upon thermal expansion of $\mathrm{La}_{2} \mathrm{Co}\left(\mathrm{Ti}_{1-x} \mathrm{Mg}_{x}\right) \mathrm{O}_{6}$ with increasing $x$. This is in agreement with the magnetic measurements, where $1 / \chi v s$ T for $x=0,0.2$ obeys the CurieWeiss law up to $773 \mathrm{~K}$, which is not the case for the $x=0.5$ sample with nominally only $\mathrm{Co}^{3+}$ (FIG. 9 and 10). The former results imply that there are no major changes in the spin state of $\mathrm{Co}^{2+}$ and $\mathrm{Co}^{3+}$ with temperature for the $\mathrm{x}=0.0$ and 0.2 samples, while for $x=0.5$ LS to HS transition upon heating is clearly seen as changes in the magnetic susceptibility. Obtained magnetic moments for $x=0.2$ and 0.5 corresponds to that the $x=0.2$ sample contains $\sim 84 \%$ of $\mathrm{HS} \mathrm{Co}^{3+}$, while the $x=0.5$ sample contains $\sim 57 \%$ of $\mathrm{HS} \mathrm{Co}^{3+}$ at $800 \mathrm{~K}$.

With the decrease of the $(\mathrm{Mg}, \mathrm{Ti}) / \mathrm{Co}$ ratio in $\mathrm{La}_{2} \mathrm{Co}_{1+z}\left(\mathrm{Ti}_{0.5} \mathrm{Mg}_{0.5}\right)_{1-z} \mathrm{O}_{6}$, with $z=0.2-0.6$, the effect of changing the $\mathrm{Mg} / \mathrm{Ti}$-cation content on the spin state of $\mathrm{Co}^{3+}$ becomes weaker. Therefore the spin state of $\mathrm{Co}^{3+}$ at certain compositions becomes only temperature dependent. The TEC for $z=0.2,0.4$ and 0.6 are very similar and correspond to what has been observed for $\mathrm{LaCoO}_{3}{ }^{10}$. Obviously, the effect of $\mathrm{Co}^{3+}$ spin-transitions on the TEC gets saturated for $60 \%(z=0.2)$ of $\mathrm{Co}^{3+}$ at the $B$-site. Thus, for the compositions with different amount of total $\mathrm{Co}^{3+}$, the spin-state transitions of the $\mathrm{Co}^{3+}$ ions do not add up into large TEC:s as a linear accumulation. The structural changes for the rhombohedral $\mathrm{La}_{2} \mathrm{Co}_{1+z}\left(\mathrm{Ti}_{0.5} \mathrm{Mg}_{0.5}\right)_{1-z} \mathrm{O}_{6}$ compounds with $z$ are obviously too small to be seen in the TEC.

\section{Electronic conductivity and Seebeck measurements}

The electronic conductivities of the compounds increase both with increasing $\mathrm{Co}^{3+} / \mathrm{Co}^{2+}$ ratio for $\mathrm{La}_{2} \mathrm{Co}\left(\mathrm{Ti}_{1-x} \mathrm{Mg}_{x}\right) \mathrm{O}_{6}$ and with increasing total $\mathrm{Co}^{3+}$ content in $\mathrm{La}_{2} \mathrm{Co}_{1+z}\left(\mathrm{Ti}_{0.5} \mathrm{Mg}_{0.5}\right)_{1-z} \mathrm{O}_{6}$. Even at high temperatures where the difference in conductivities between different compositions becomes smaller, this trend is clearly seen as depicted in the right part of FIG. 
4. From the decreasing Seebeck coefficients with increasing amount of $\mathrm{Co}^{3+}$ it is clear that this is due to a simultaneous increase of the number of charge carriers. The Seebeck coefficients are positive for all compositions in the whole studied temperature range except for the $\mathrm{La}_{2} \mathrm{Co}_{1.6}\left(\mathrm{Ti}_{0.5} \mathrm{Mg}_{0.5}\right)_{0.4} \mathrm{O}_{6}$ sample, that becomes negative at $T<390 \mathrm{~K}$. Therefore all studied compounds are $p$-type conductors, except the latter one at $T<390 \mathrm{~K}$.

For the first group of compositions $\left(\mathrm{La}_{2} \mathrm{Co}\left(\mathrm{Ti}_{1-x} \mathrm{Mg}_{x}\right) \mathrm{O}_{6}, x=0.0\right.$ and 0.1$)$ mentioned above, the Seebeck coefficient is relatively high and positive, although $\mathrm{Ti}^{4+}$ should be an $n$-type dopant. This result is in agreement with what was reported for $\mathrm{La}_{2} \mathrm{CoTiO}_{6}(x=0.0)$ by Nakatsugawa et al. ${ }^{26}$ and $\mathrm{LaCo}_{1-x} \mathrm{Ti}_{x} \mathrm{O}_{3}, x=0.01,0.1$ and 0.2 by some of us ${ }^{2}$. The $p$-type conduction is obtained as the electrons become trapped by the extra bands created by $\mathrm{Ti}^{4+}$ impurity levels when the $\mathrm{Ti}^{4+}$ is abundant and ordered in the structure and the electron mobilities thus decrease. ${ }^{27,28}$ The temperature dependence of the conductivity for the first group of compositions exhibit a semiconducting behaviour with constant activation energy over the whole studied temperature range. It should be mentioned that activation energies of conductivities for samples belonging to first group are by $c a .30 \%$ lower in comparison with the first compositions ( $x=0.2$ and 0.3 ) of the second group (FIG. 4, left side), therefore reflecting the importance of the $B$-cation disorder effect. It is attributed to an increased difficulty for the charge carriers to jump between different sites in the crystal, mainly due to an increasing probability of having a $\mathrm{Mg}^{2+}$ ion nearby a Co ion. This would hinder the small polarons, resulting in larger activation energies.

For the second group of compositions, with complete disorder on the $B$-cation site, an increase in conductivity and decrease in average activation energy with increasing of $\mathrm{Mg}^{2+}$ content is observed (FIG. 4). Charge-carrier concentration increases as the amount of $\mathrm{Co}^{3+}$ increases as can be observed from measurements of the Seebeck coefficient. The non-linear behaviours of the conductivities observed at higher temperatures are due to lowering of the activation energy. It starts around $T=973 \mathrm{~K}$ for $x=0.2$ where the change is rather small, but for the samples with $x>0.3$ it is significant and shifts to lower temperatures with increasing $x$. It can be ascribed to the temperature dependence of the disproportion reaction of $\mathrm{Co}^{3+}$. It is known that the conductivity in $\mathrm{Co}^{3+}$ containing perovskites is promoted by disproportionation according to the reaction equation $2 \mathrm{Co}^{3+} \rightarrow \mathrm{Co}^{2+}+\mathrm{Co}^{4+}$. The disproportionation equilibrium is further shifted to the right side for $\mathrm{Co}^{3+}$ in $\mathrm{HS}$ state.$^{13}$ It should be mentioned that the 
equilibrium constant of this reaction, $K=\frac{\left\lfloor\mathrm{Co}^{2+}\left\lfloor\mathrm{Co}^{4+}\right\rfloor\right.}{\left[\mathrm{Co}^{3+}\right]^{2}}$, increases with temperature. The equilibrium of the disproportionation reaction is shifted towards the $\mathrm{Co}^{3+}$ side for $\mathrm{La}_{2} \mathrm{Co}\left(\mathrm{Ti}_{1-}\right.$ $\left.{ }_{x} \mathrm{Mg}_{x}\right) \mathrm{O}_{6}$ in comparison with undoped $\mathrm{LaCoO}_{3}$ due to the presence of $\mathrm{Co}^{2+}$ and to the increasing proportion of $\mathrm{LS} \mathrm{Co}^{3+}$, as mentioned above. It is obvious that the proportion of $\mathrm{Co}^{2+} / \mathrm{Co}^{3+}$ and the LS/HS ratio for $\mathrm{Co}^{3+}$ changes in opposite directions with $x$. However, the decreasing of the upper temperature limit for the linear behaviour of the conductivity $v s$. temperature with increasing $\mathrm{Co}^{3+}(x)$ shows that $\mathrm{Co}^{2+} / \mathrm{Co}^{3+}$ ratio is more important in the case of $\mathrm{La}_{2} \mathrm{Co}\left(\mathrm{Ti}_{1-\mathrm{x}} \mathrm{Mg}_{\mathrm{x}}\right) \mathrm{O}_{6}$ perovskites.

For the third group of compositions with only $\mathrm{Co}^{3+}$ a large increase in conductivity together with a decrease of activation energy occurs with increasing of cobalt content. This can be explained by an expansion of the conductive network of $\mathrm{Co}^{3+}$ ions on the way to $\mathrm{LaCoO}_{3}$. Moreover, trends in temperature dependences of both conductivity and Seebeck coefficient are similar to those for substituted $\mathrm{LaCoO}_{3}$. At $T<473 \mathrm{~K}$, low $(z=0.4)$, or even small negative $(z=0.6)$ Seebeck coefficients are observed, which can be related to an increased or even higher mobility of the electrons than found for the holes at lower temperatures ${ }^{26,29-32}$ This resembles the behaviour of $n$-doped $\mathrm{LaCoO}_{3}$ (i.e. slightly oxygen deficient $\mathrm{LaCoO}_{3-\delta}$ after treatment in reducing atmosphere or by $\mathrm{Ti}^{4+}$ doping. ${ }^{30,31}$ The Seebeck coefficients then increase with temperature as the electrons are recombining with the holes formed. This reaches a maximum at $T \approx 653 \mathrm{~K}$, after which it decreases again as the number of hole carrier continues to increase by the formation of charge carriers through disproportionation of $\mathrm{Co}^{3+}$ to $\mathrm{Co}^{4+}$ and $\mathrm{Co}^{2+}$. At higher temperatures the Seebeck coefficients of the samples with $x=0.5$ along the $\mathrm{La}_{2} \mathrm{Co}_{1+z}\left(\mathrm{Ti}_{0.5} \mathrm{Mg}_{0.5}\right)_{1-z} \mathrm{O}_{6}$ series converges towards a positive value in the range 35$50 \mu \mathrm{V} / \mathrm{K}$ at $T \approx 1173 \mathrm{~K}$. This is similar to what has been reported for slightly $n$-doped $\mathrm{LaCoO}_{3}{ }^{2,30,31}$

\section{Conclusions}

The studied system $\mathrm{La}_{2} \mathrm{Co}_{1+z}\left(\mathrm{Ti}_{1-x} \mathrm{Mg}_{x}\right)_{1-z} \mathrm{O}_{6}$ represents a rare example of Co-containing perovskites with $3 \mathrm{D}$ octahedral network, where it is possible to study correlations between cobalt oxidation state only and various high-temperature properties. Based on the temperature dependence of the thermal expansion, electronic transport properties and Seebeck coefficients, three different groups of compositions can be allocated. First group is $\mathrm{La}_{2} \mathrm{Co}\left(\mathrm{Ti}_{1}\right.$ $\left.{ }_{x} \mathrm{Mg}_{x}\right) \mathrm{O}_{6}, x=0.0$ and 0.1 with ordered $\mathrm{Co}^{2+}$ and $\mathrm{Ti}^{4+}$ cations in the crystal structure. Second 
group includes samples of $\mathrm{La}_{2} \mathrm{Co}\left(\mathrm{Ti}_{1-x} \mathrm{Mg}_{x}\right) \mathrm{O}_{6}, x=0.2-0.4$, while the third one merges compositions $\mathrm{La}_{2} \mathrm{Co}_{1+z}\left(\mathrm{Ti}_{0.5} \mathrm{Mg}_{0.5}\right)_{1-\mathrm{z}} \mathrm{O}_{6}, z=0.2$ - 0.6 with $\mathrm{Co}^{3+}$-only. We did not observe any influence from the detailed crystal structures (except the ordering at the $B$-site for $x \leq 0.2$ ) like changes in tilting of the octahedra on the studied high-temperature properties. The thermal expansion behaviours of the studied compounds are mainly dependent on the proportion of $\mathrm{Co}^{2+} / \mathrm{Co}^{3+}$. For $\mathrm{La}_{2} \mathrm{Co}\left(\mathrm{Ti}_{1-x} \mathrm{Mg}_{x}\right) \mathrm{O}_{6}$ TEC increases from $\sim 9(x=0)$ to $19 \mathrm{ppmK}^{-1}(x=0.5)$ with an increase of the oxidation state of cobalt from +2 and +3 , respectively. However, the increase is not linear with increasing $\mathrm{Co}^{3+}$-content because the LS/HS ratio for $\mathrm{Co}^{3+}$ is dependent on magnesium content. The main reason for this is the so-called chemical pressure effect caused by the presence of large $\mathrm{Mg}^{2+}$ on neighbouring $\mathrm{Co}^{3+}$. This conclusion is supported by magnetic susceptibility measurements performed on samples with different oxidation states of cobalt. The thermal expansion $\mathrm{La}_{2} \mathrm{Co}_{1+z}\left(\mathrm{Ti}_{0.5} \mathrm{Mg}_{0.5}\right)_{1-z} \mathrm{O}_{6}, z=0.2-0.6$ with $\mathrm{Co}^{3+}$-only, remains constant at $\sim 21 \mathrm{ppmK}^{-1}$ independently of the cobalt content. All studied compounds present $p$-type conductivity, except $\mathrm{La}_{2} \mathrm{Co}_{1.6}\left(\mathrm{Ti}_{0.5} \mathrm{Mg}_{0.5}\right)_{0.4} \mathrm{O}_{6}$ at $T<390 \mathrm{~K}$. The electronic conductivities were found to increase with an increase of both $\mathrm{Co}^{3+}$ and total cobalt content and are described using a small polaron hopping model.

\section{Acknowledgements}

The authors want to thank the Visbyprogramme at Swedish Institute, Swedish research council, SNF (Swiss national Science Foundation) and the Ministry of Science and Education of Russian Federation (state contract 14.740.12.1358) for financial support. The authors are grateful to E. Brücher for measurement of the magnetic data.

\section{References}

${ }^{1}$ N. Ramadass, J. Gopalakrishnan, and M.V.C. Sastri, J. Less-Common Met. 65, 129-138 (1979).

${ }^{2}$ R. Robert, L. Bocher, M. Trottmann, A. Reller, and A. Weidenkaff, J. Solid State Chem. 179, 3893-3899 (2006).

${ }^{3}$ A. Podlesnyak, K. Conder, E. Pomjakushina, A. Mirmelstein, P. Allenspach, and D. Khomskii, J. Magn. Magn. Mater. 310, 1552-1554 (2007).

${ }^{4}$ P.G. Radaelli and S.-W. Cheong, Phys. Rev. B: Condens. Matter 66, 1-9 (2002).

${ }^{5}$ D. Tsvetkov, A. Zuev, A. Vylkov, and A. Petrov, Solid State Ionics 178, 1458-1462 (2007). 
${ }^{6}$ Z.Y. Wu, M. Benfatto, M. Pedio, R. Cimino, S. Mobilio, S.R. Barman, K. Maiti, and D.D. Sarma, Phys. Rev. B: Condens. Matter 56, 2228-2233 (1997).

${ }^{7}$ M. Korotin, S. Ezhov, I. Solovyev, V. Anisimov, D. Khomskii, and G. Sawatzky, Physical Review. B, Condensed Matter 54, 5309-5316 (1996).

${ }^{8}$ M.W. Haverkort, Z. Hu, J.C. Cezar, T. Burnus, H. Hartmann, M. Reuther, C. Zobel, T. Lorenz, A. Tanaka, N.B. Brookes, H.H. Hsieh, H.-J. Lin, C.T. Chen, and L.H. Tjeng, Phys. Rev. Lett. 97, 38-41 (2006).

${ }^{9}$ A. Petric, P. Huang, and F. Tietz, Solid State Ionics 135, 719-725 (2000).

${ }^{10}$ S. Uhlenbruck and F. Tietz, Mater. Sci. Eng., B 107, 277-282 (2004).

${ }^{11}$ S. Shafeie, J. Grins, S.Y. Istomin, L. Karvonen, S. a. Chen, T.H. Chen, J.M. Chen, A. Weidenkaff, M. Karppinen, and T. Sirtl, J. Solid State Chem. 184, 177-190 (2011).

${ }^{12}$ M. Radovic, S. a. Speakman, L.F. Allard, E. a. Payzant, E. Lara-Curzio, W.M. Kriven, J. Lloyd, L. Fegely, and N. Orlovskaya, Journal of Power Sources 184, 77-83 (2008).

${ }^{13}$ R. Koc and H.U. Anderson, J. Eur. Ceram. Soc. 15, 867-874 (1995).

${ }^{14}$ J.B. Goodenough, Mater. Res. Bull. 5, 621-629 (1970).

${ }^{15}$ A.N. Petrov, A.Y. Zuev, A.I. Vylkov, and D.S. Tsvetkov, Russ. J. Phys. Chem. 80, S128S133 (2006).

${ }^{16}$ J. Lago, P.D. Battle, M.J. Rosseinsky, A.I. Coldea, and J. Singleton, J. Phys. Condens. Matter 15, 6817-6833 (2003).

${ }^{17}$ M.A. Hayward and M.J. Rosseinsky, Chem. Mater. 12, 2182-2195 (2000).

${ }^{18}$ P. Ravindran, P.A. Korzhavyi, H. Fjellvåg, and A. Kjekshus, Phys. Rev. B: Condens. Matter 60, 16423-16434 (1999).

${ }^{19}$ R. Robert, D. Logvinovich, M.H. Aguirre, S.G. Ebbinghaus, L. Bocher, P. Tomeš, and A. Weidenkaff, Acta Mater. 58, 680-691 (2010).

${ }^{20}$ I. Álvarez-Serrano, G.J. Cuello, M.L. López, A. Jiménez-López, C. Pico, E. RodríguezCastellón, E. Rodríguez, and M.L. Veiga, J. Phys. D: Appl. Phys. 41, 195001 (2008).

${ }^{21}$ M. Yuste, J.C. Pérez-Flores, J.R. de Paz, M.T. Azcondo, F. García-Alvarado, and U. Amador, Dalton Trans. 40, 7908-15 (2011).

${ }^{22}$ S. Yamauchi, T. Ishigaki, J. Mizusaki, and K. Fueki, Solid State Ionics 9-10, 997-1000 (1983).

${ }^{23}$ L.B. Sis, G.P. Wirtz, and S.C. Sorenson, J. App. Phys. 44, 5553-5559 (1973). 
${ }^{24}$ V.V. Kharton, F.M. Figueiredo, A.V. Kovalevsky, A.P. Viskup, E.N. Naumovich, A.A. Yaremchenko, I.A. Bashmakov, and F.M.B. Marques, J. Eur. Ceram. Soc. 21, 2301-2309 (2001).

${ }^{25}$ C.F. Chang, Z. Hu, H. Wu, T. Burnus, N. Hollmann, M. Benomar, T. Lorenz, A. Tanaka, H.-J. Lin, H.H. Hsieh, C.T. Chen, and L.H. Tjeng, Phys. Rev. Lett. 102, 1-4 (2009).

${ }^{26}$ H. Nakatsugawa and E. Iguchi, J. Phys. Condens. Matter 11, 1711-1722 (1999).

${ }^{27}$ P.M. Raccah and J.B. Goodenough, J. Appl. Phys. 39, 1209 (1968).

${ }^{28}$ J.B. Goodenough, Czech. J. Phys. B17, 304-336 (1967).

${ }^{29}$ D. Bahadur and O. Parkash, J. Solid State Chem. 46, 197-203 (1983).

${ }^{30}$ J. Hejtmánek, Z. Jirák, K. Knížek, M. Marysko, M. Veverka, and C. Autret, J. Magn. Magn. Mater. 320, e92-e95 (2008).

${ }^{31}$ Z. Jirák, J. Hejtmánek, K. Knížek, and M. Veverka, Phys. Rev. B: Condens. Matter 78, 1-8 (2008).

${ }^{32}$ S. Hebert, D. Flahaut, C. Martin, S. Lemonnier, J. Noudem, C. Goupil, A. Maignan, and J. Hejtmanek, Prog. Solid State Chem. 35, 457-467 (2007). 


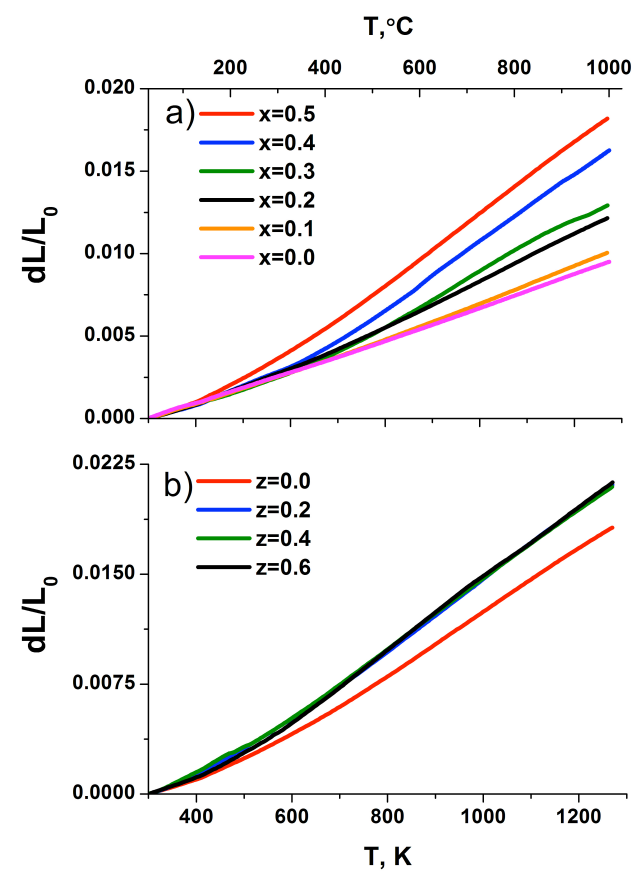

FIG. 1 Linear thermal expansion for (a) $\mathrm{La}_{2} \mathrm{Co}\left(\mathrm{Ti}_{1-x} \mathrm{Mg}_{x}\right) \mathrm{O}_{6}(0 \leq x \leq 0.5)$ and (b) $\mathrm{La}_{2} \mathrm{Co}_{1+z}\left(\mathrm{Ti}_{0.5} \mathrm{Mg}_{0.5}\right)_{1-z} \mathrm{O}_{6}$ $(0 \leq z \leq 0.6)$. The bottom curve corresponds to $x=0$ and $z=0$ in FIG. 1 a and $b$ respectively, thereafter they follow with increasing values to the uppermost curve with the $x$ and $z$ values.

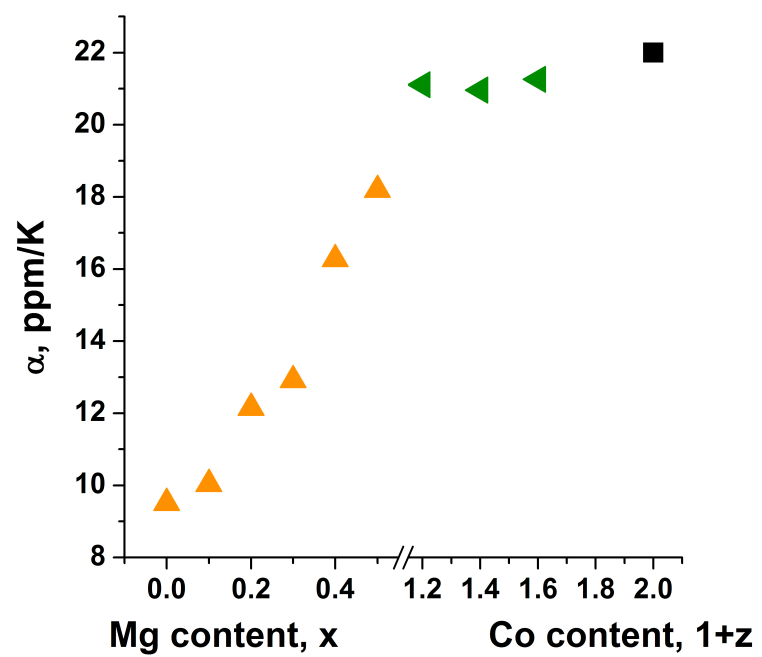

FIG. 2 Average linear thermal expansion coefficient (TEC) at temperatures 298 - $1273 \mathrm{~K}$ (left) for $\mathrm{La}_{2} \mathrm{Co}\left(\mathrm{Ti}_{1-\mathrm{x}} \mathrm{Mg}_{\mathrm{x}}\right) \mathrm{O}_{6}$ as a function of $\mathrm{x}$ and (right) for $\mathrm{La}_{2} \mathrm{Co}_{1+z}\left(\mathrm{Ti}_{0.5} \mathrm{Mg}_{0.5}\right)_{1-\mathrm{z}} \mathrm{O}_{6}$ as a function of $1+\mathrm{z}$. The value for $\mathrm{LaCoO}_{3}$ has been inserted as reference (black square). ${ }^{12}$ 


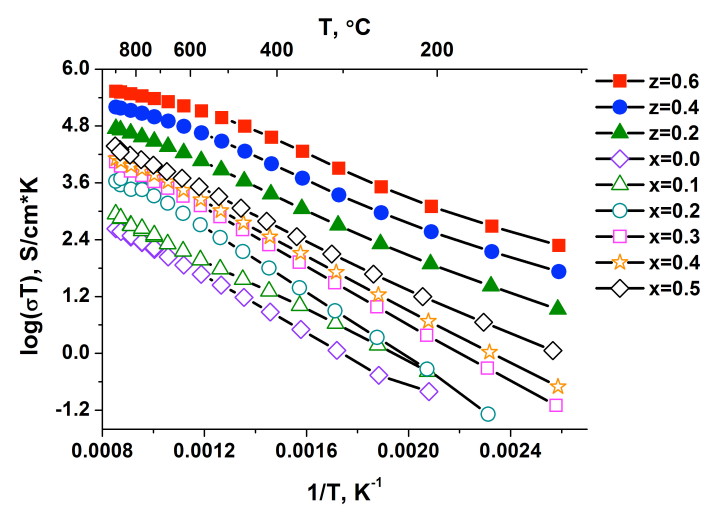

FIG. 3 Arrhenius plot of the high temperature electronic conductivity data $\log (\sigma T)$ vs. $1 / T$ of $\mathrm{La}_{2} \mathrm{Co}\left(\mathrm{Ti}_{1}\right.$ $\left.{ }_{x} \mathrm{Mg}_{x}\right) \mathrm{O}_{6}(0 \leq x \leq 0.5)$ and $\mathrm{La}_{2} \mathrm{Co}_{1+z}\left(\mathrm{Ti}_{0.5} \mathrm{Mg}_{0.5}\right)_{1-z} \mathrm{O}_{6}(0 \leq z \leq 0.6)$

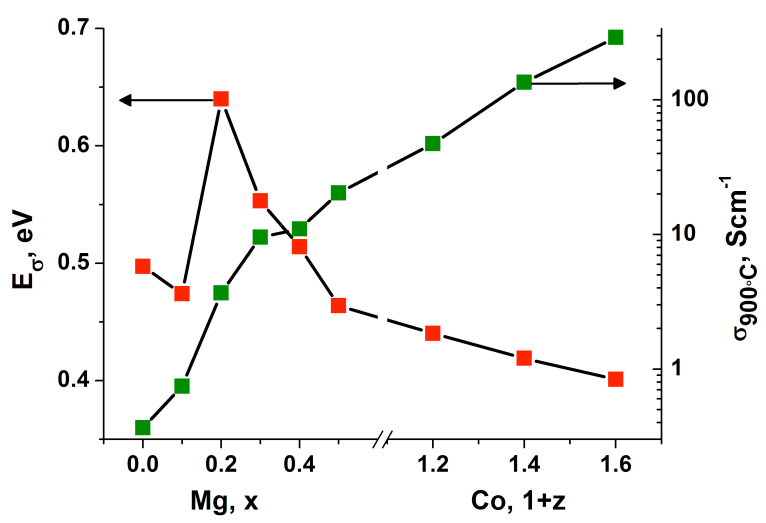

FIG. 4 The variation of the electronic conductivity at $T=1173 \mathrm{~K}$ (green symbols) and the corresponding activation energies (red symbols) for the compositions $\mathrm{La}_{2} \mathrm{Co}\left(\mathrm{Ti}_{1-x} \mathrm{Mg}_{x}\right) \mathrm{O}_{6}(0 \leq x \leq 0.5)$ and $\mathrm{La}_{2} \mathrm{Co}_{1+z}\left(\mathrm{Ti}_{0.5} \mathrm{Mg}_{0.5}\right)_{1-z} \mathrm{O}_{6}(0 \leq z \leq 0.6)$

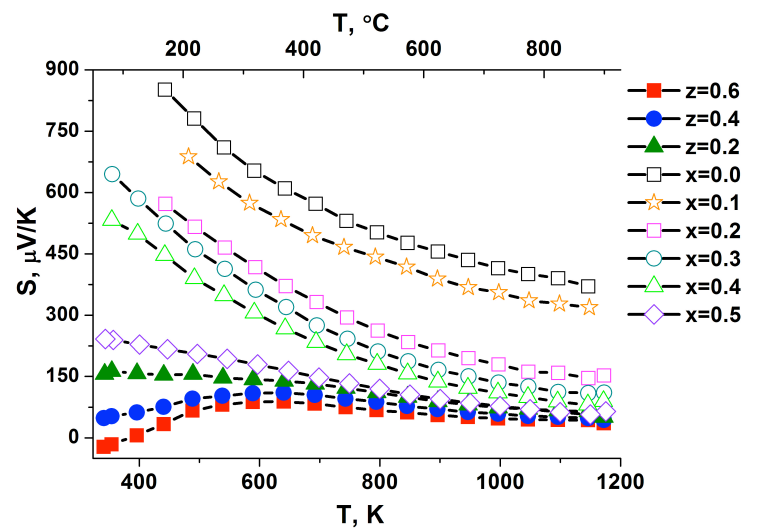

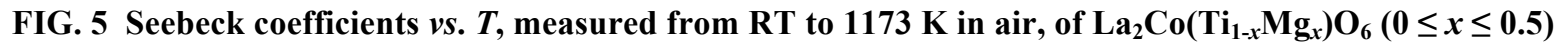
and $\mathrm{La}_{2} \mathrm{Co}_{1+z}\left(\mathrm{Ti}_{0.5} \mathrm{Mg}_{0.5}\right)_{1-z} \mathrm{O}_{6}(0 \leq z \leq 0.6)$. 


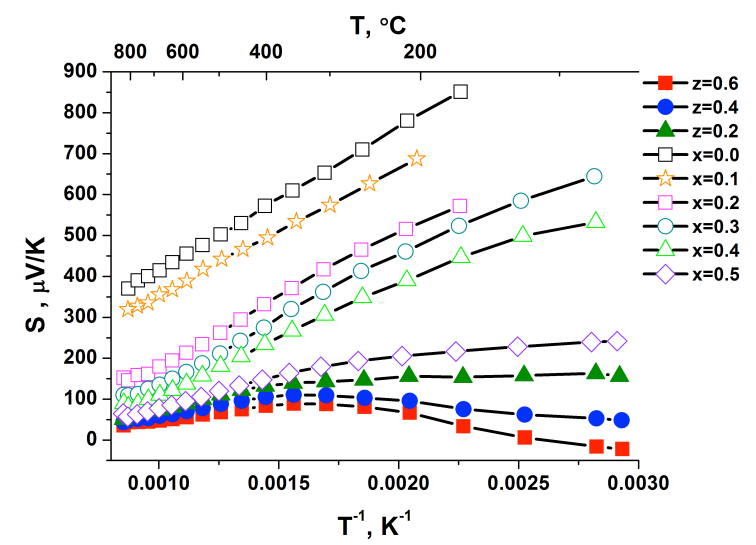

FIG. 6 Seebeck coefficients $v s .1 / T$, measured from $\mathrm{RT}$ to $1173 \mathrm{~K}$ in air, of $\mathrm{La}_{2} \mathrm{Co}_{(}\left(\mathrm{Ti}_{1-x} \mathrm{Mg}_{x}\right) \mathrm{O}_{6}(0 \leq x \leq 0.5)$ and $\mathrm{La}_{2} \mathrm{Co}_{1+z}\left(\mathrm{Ti}_{0.5} \mathrm{Mg}_{0.5}\right)_{1-z} \mathrm{O}_{6}(0 \leq z \leq 0.6)$. A linear Arrhenius behaviour is observed in the temperature range $\sim 643-1143 \mathrm{~K}$.

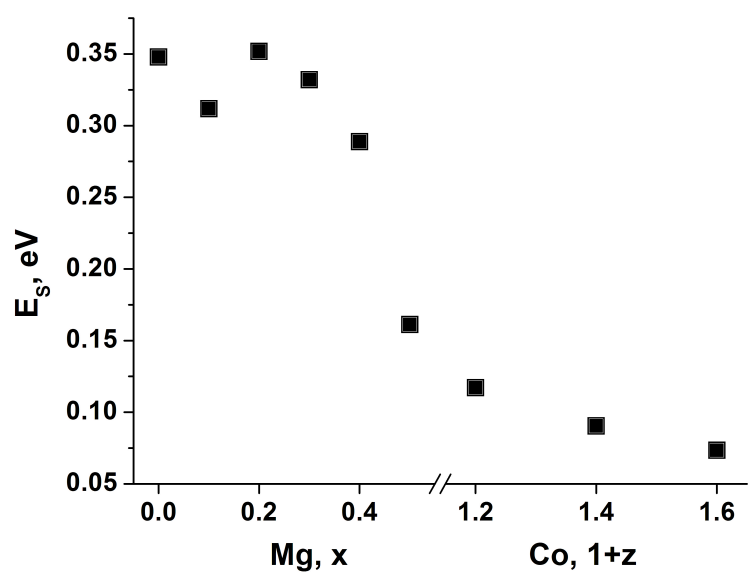

FIG. 7 Corresponding values for the energy of polaron ionization $\left(E_{S}\right)$ calculated from the Seebeck coefficients $v s .1 / T$ in the linear temperature range $\sim 643-1143 \mathrm{~K}$ for $\mathrm{La}_{2} \mathrm{Co}\left(\mathrm{Ti}_{1-x} \mathrm{Mg}_{x}\right) \mathrm{O}_{6}(0 \leq x \leq 0.5)$ and $\mathrm{La}_{2} \mathrm{Co}_{1+z}\left(\mathrm{Ti}_{0.5} \mathrm{Mg}_{0.5}\right)_{1-z} \mathrm{O}_{6}(0 \leq z \leq 0.6)$

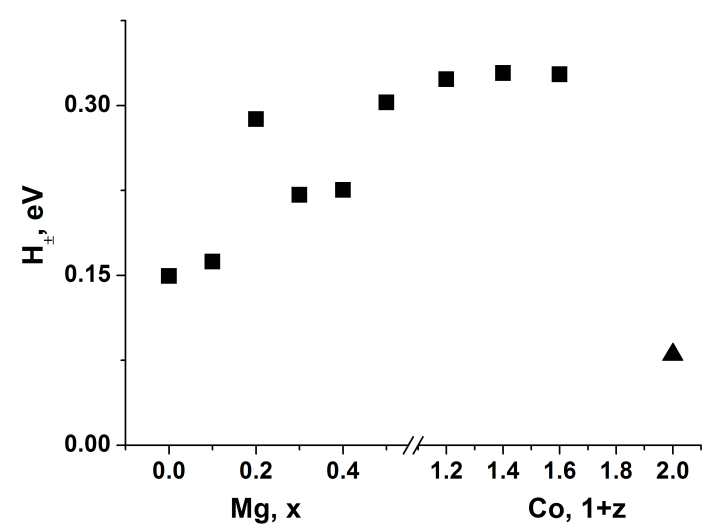

FIG. 8 Compositional variation of the heats of charge carrier jump, $\mathrm{H}_{ \pm}(\mathrm{eV})$. The value for $\mathrm{LaCoO}_{3}$ has been inserted as a reference (black triangle). ${ }^{15}$ 


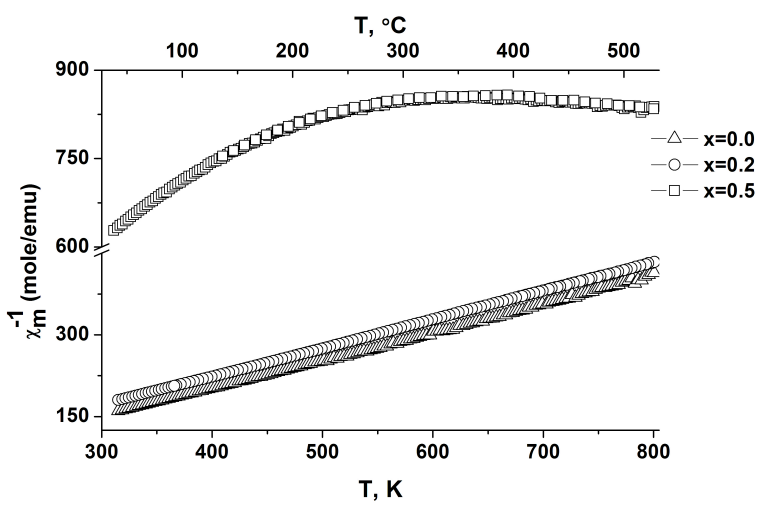

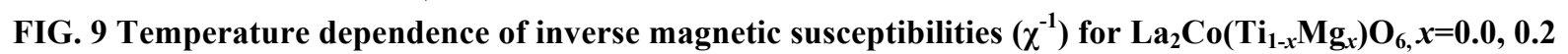
and 0.5 samples.

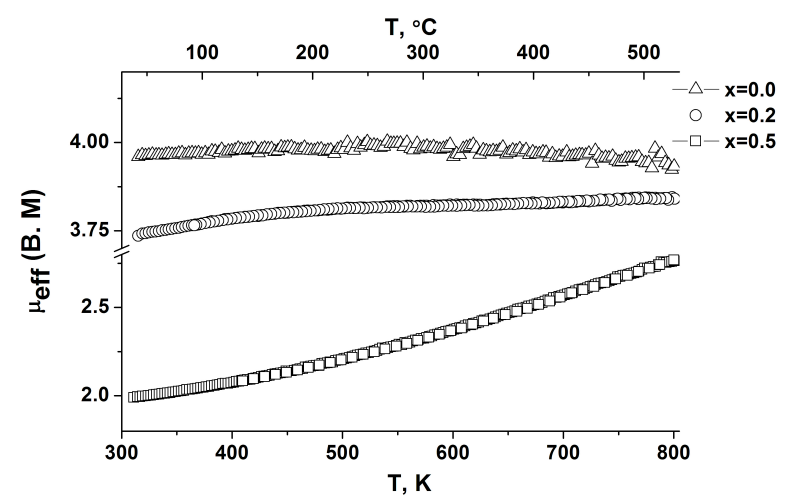

FIG. 10 Temperature dependence of the calculated magnetic moments $\left(\mu_{\mathrm{eff}}\right)$ for $\mathrm{La}_{2} \mathrm{Co}_{0}\left(\mathrm{Ti}_{1-\mathrm{x}} \mathrm{Mg}_{\mathrm{x}}\right) \mathrm{O}_{6}, \mathbf{x}=0.0$, 0.2 and 0.5 samples. 